\title{
Study of Light Wavelength and Some Concentration Salts in Growth Medium on Growth, Protein and Nitrogen Content of Hapalosiphon arboreus $30 \mathrm{W05S02}$
}

\author{
Fatin Mahdi Saleh Al-Rashidy ${ }^{*}$, Yousef Jabar Al-Shaheree ${ }^{2}$ \\ ${ }^{1 *, 2}$ Department of Biology, College of Education for Pure Sciences, University of Mosul, Mosul, Iraq \\ E-mail: ${ }^{1 *}$ fatinbio91@gmail.com, ${ }^{2}$ yousefalshahery@uomosul.edu.iq
}

(Received November 21, 2020; Accepted January 18, 2021; Available online June 01, 2021)

DOI: 10.33899/edusj.2021.128991.1122, (c) 2021, College of Education for Pure Science, University of Mosul.

This is an open access article under the CC BY 4.0 license (http://creativecommons.org/licenses/by/4.0/).

\begin{abstract}
Local isolation was obtained from cyanobacteria fixing atmospheric nitrogen, and isolated from the local environment of the city of Mosul (Tigris River forest area). This isolation was grown laboratory in the medium of $\mathrm{Chu}_{10}$. As for the change of wavelengths of light, the red light results showed that the best wavelength of light was $(620-750) \mathrm{nm}$, the biomass is (770) $\mathrm{mg} / \mathrm{L}$, the protein content is (230) $\square \mathrm{g} / \mathrm{ml}$, while the nitrogen content is (119) $\mathrm{mg} / \mathrm{L}$. Also I studied a number of mineral elements that affected on growth and nitrogen content, and it was found that the best concentration of potassium phosphate $\mathrm{K}_{2} \mathrm{HPO}_{4}$ is $(50) \mathrm{mg} / \mathrm{L}$, as recorded the biomass is (802) $\mathrm{mg} / \mathrm{L}$, the protein content is (202) $\square \mathrm{g} / \mathrm{ml}$, and the nitrogen content is (107) $\mathrm{mg} / \mathrm{L}$. When adding different concentrations of $\mathrm{Ca}\left(\mathrm{No}_{3}\right)_{2}$ to the medium and comparing them without adding this material to the medium, the best concentration was $(60) \mathrm{mg} / \mathrm{L}$, the biomass is $(790) \mathrm{mg} / \mathrm{L}$, the protein content is (138) $\square \mathrm{g} / \mathrm{ml}$, and the nitrogen content is (74) $\mathrm{mg} / \mathrm{L}$.
\end{abstract}

Keywords: Hapalosiphon, Nitrogen Fixation, Heterocystis

\section{دراسة تأثير الطول الموجي للضوء وتركيز بعض الأملاح في وسط التنمية على النمو والمحتوى البروتيني والنايتروجيني للطحلب Hapalosiphon arboreus 3OW05S02}

$$
\begin{aligned}
& \text { فاتن مهاي صالح الراشدي1*، يوسف جبار الثاهري2 } \\
& \text { 1*،2قسم علوم الحياة، كلية التربية للعلوم الصرفة، جامعة الموصل }
\end{aligned}
$$

تم الحصول على عزلة محلية من السيانوبكتريا المثبتة للنيتروجين الجوي من منطقة الغابات ـ نهر دجلة ـ مدينة الموصل Hapalosiphon arboreus 3OW05S02

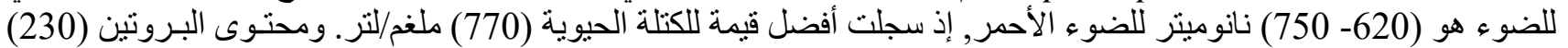

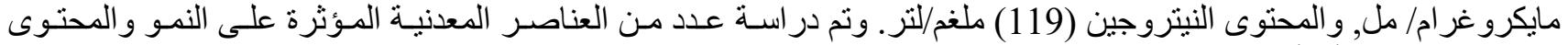

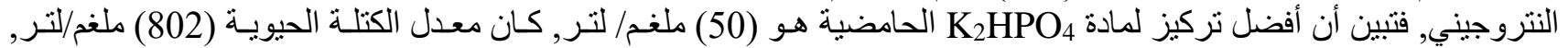

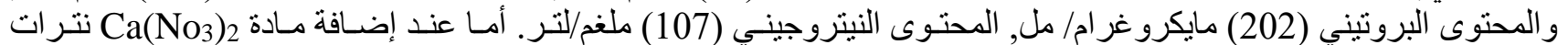

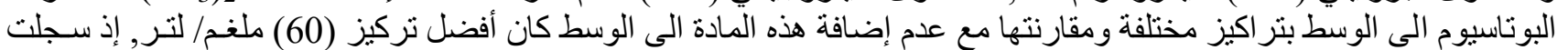

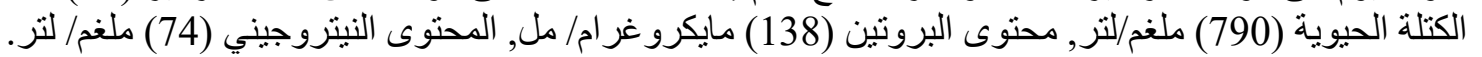

$$
\text { الكلمات المفتاحية: Hapalosiphon, تنيبت النيتروجين, الحويصلات المتغايرة . }
$$




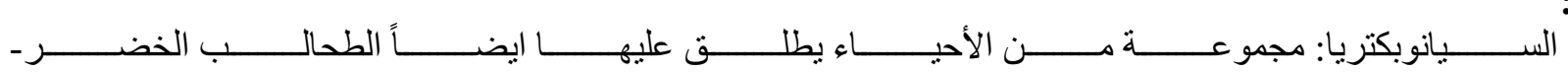

المقدمة:

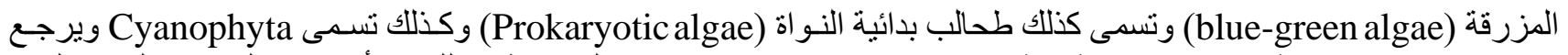

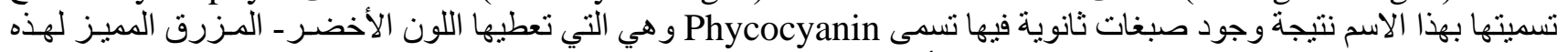

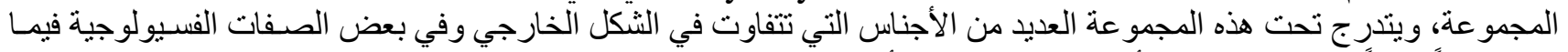

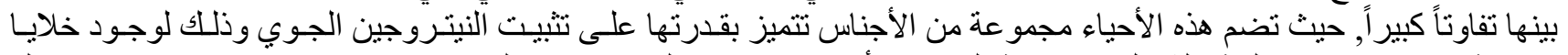

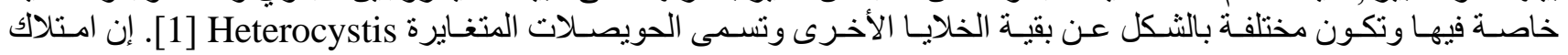

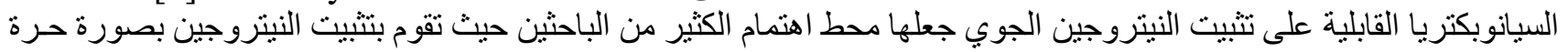

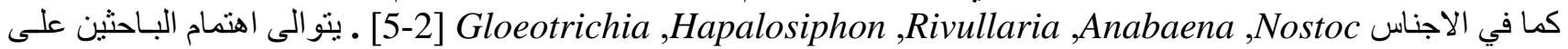

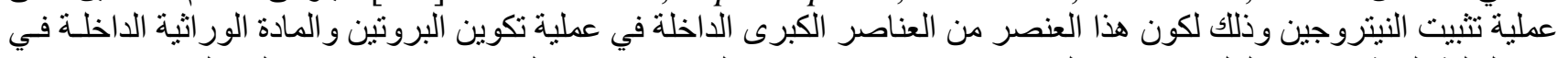

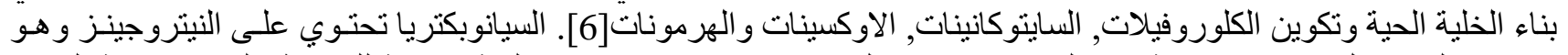

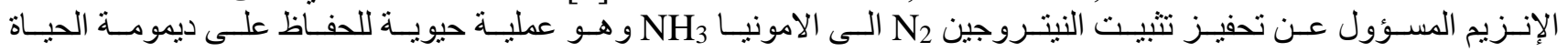

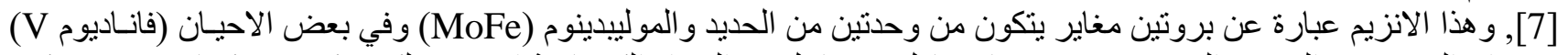

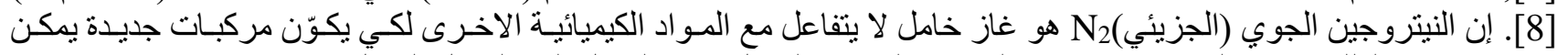

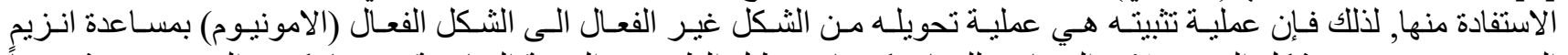

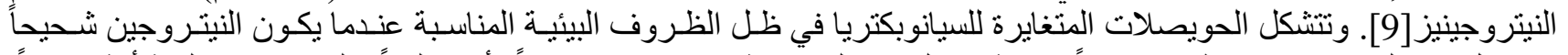

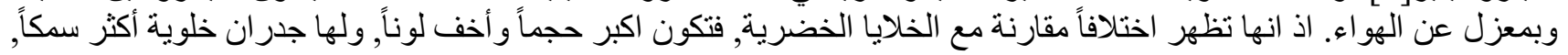

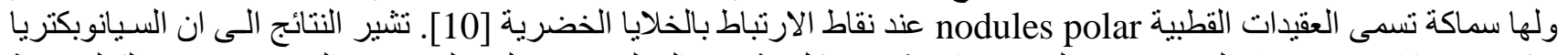

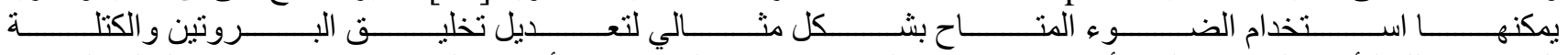

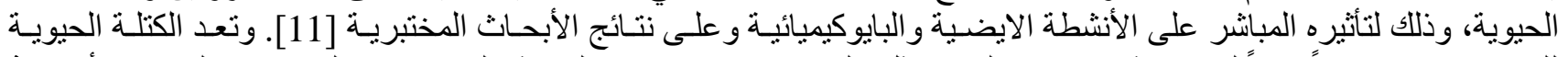

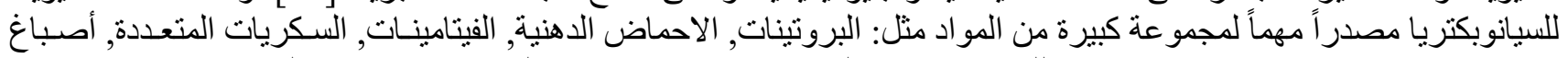

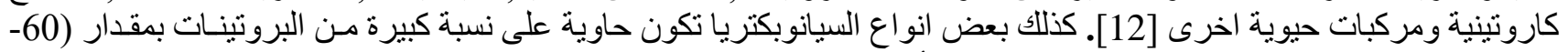

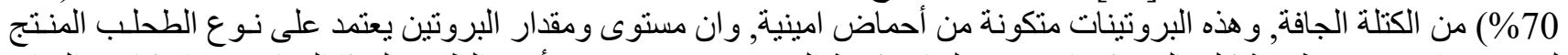

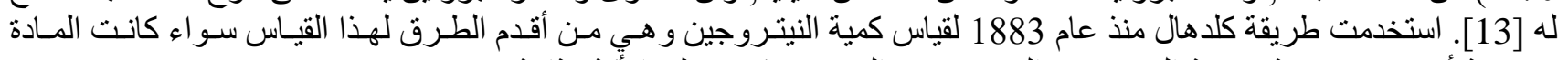

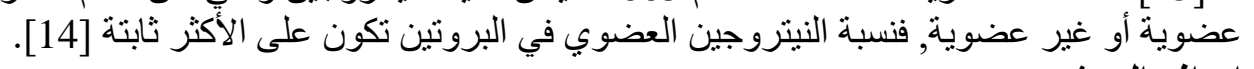

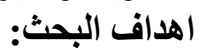

تحديد الظروف الزروعية المثلى ومعرفة تأثثير الاطو ال الموجية المختلفة على زيادة النمو وتحسين المحتوى النيتروجينـي

و البروتني و الكتلة الحوية للسلالة المعزولة محليا Hapalosiphon arboreus 3OW05S02. مواد وطرق العمل

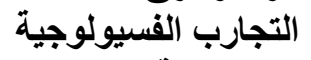
جمع العينة وعزلها تجاربية

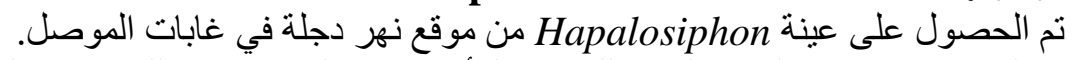

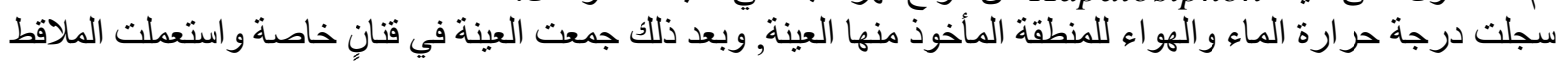

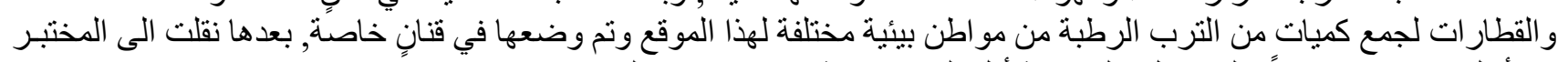

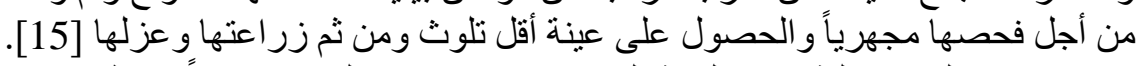

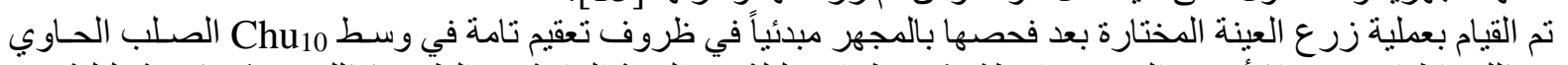

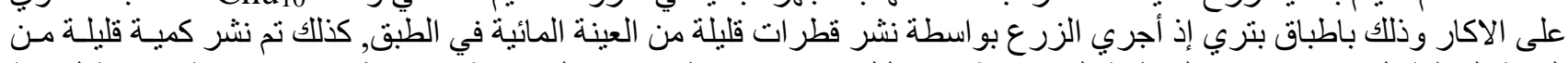

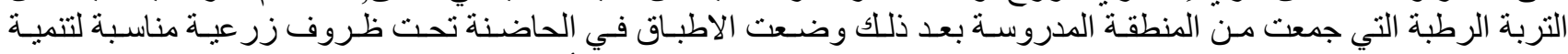

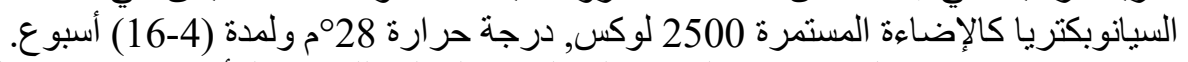

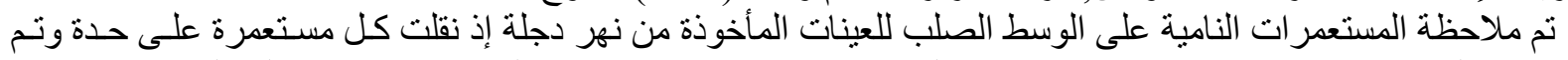
زر اعتها بطريقة التخطيط streaking method وطريقة التخفيف Dilution method على وسط الفيط

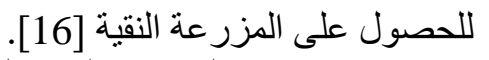

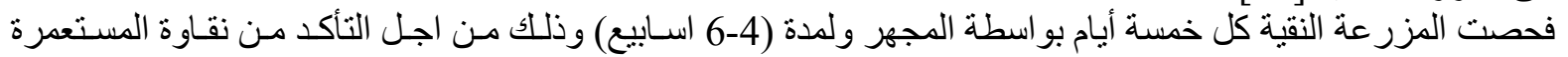
لجنس السيانوبكتريا المدروسة. 


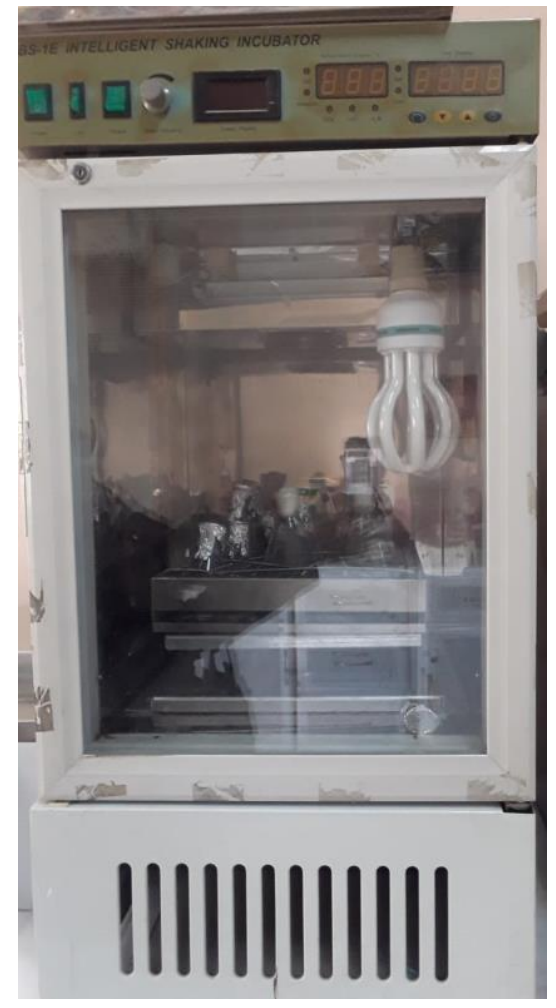

\section{حاضنة من نوع BS-1Eintelligent shaking incubator}

الوسط الزرعي و الظروف الزرعية المناسبة لتنمية الطحلب السياني قيد الارعاسة

Culture medium and the agricultural conditions for growing of Hapalosiphon arboreus :

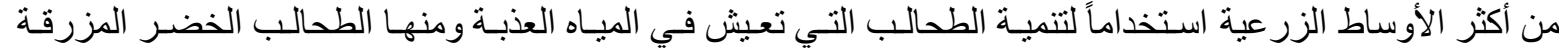

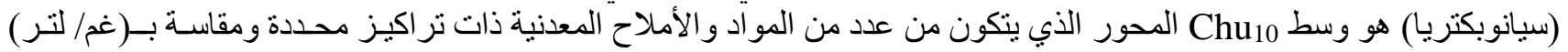

$\begin{array}{cc}\text { الوزن غلت المادة } \\ 0.4 & \mathrm{Ca}\left(\mathrm{NO}_{3}\right)_{2} \\ 0.1 & \mathrm{~K}_{2} \mathrm{HPO}_{4} \\ 0.2 & \mathrm{Na}_{2} \mathrm{CO}_{3} \\ 0.25 & \mathrm{Mg} \mathrm{SO}_{4} .7 \mathrm{H}_{2} \mathrm{O} \\ 0.25 & \mathrm{Na} \mathrm{SiO}_{3}\end{array}$

من الماء المقطر [18]: مهبان

$0.05 \quad$ Ferric Ammonium Citrate

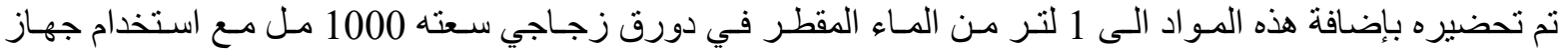

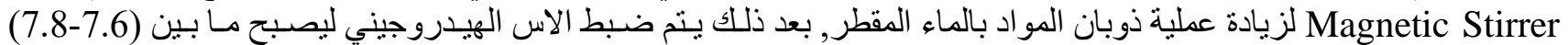

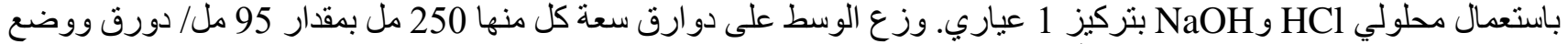

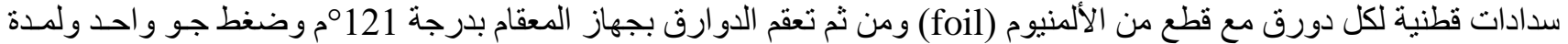
20

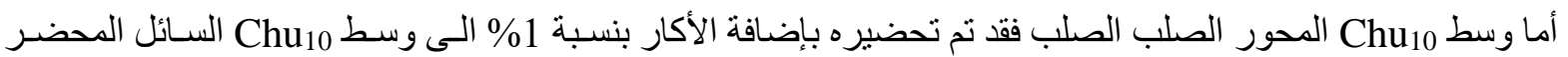

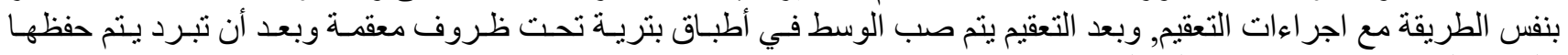

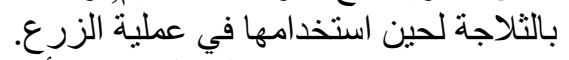

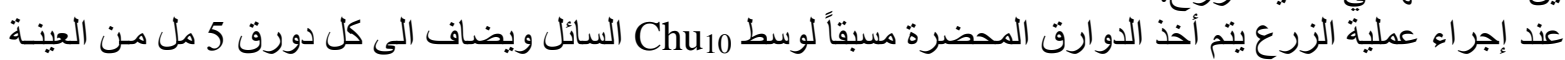

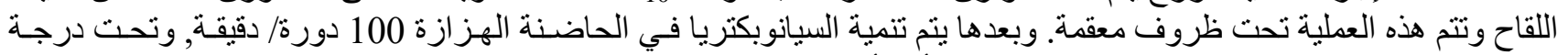

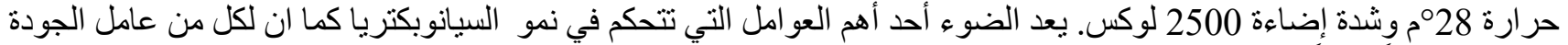

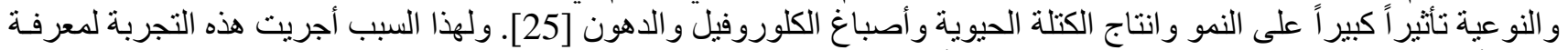

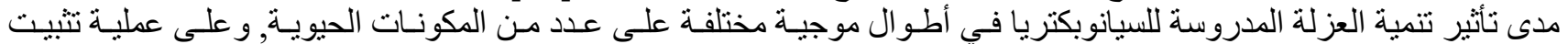
النيتروجين, حيث وضعت التير تلعينة المزروعة في وسط Chu nm750, الأخضر nm570-495, الأزرق nm450-450) لمدة 15 يوم لكل معاملة. 


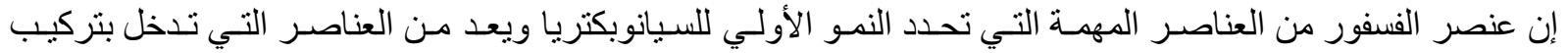

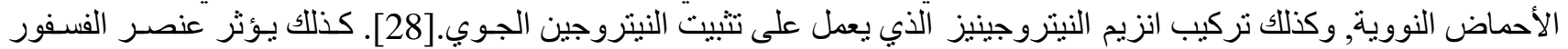
بالتر اكيز العالية حيث استخدمت ستة تر اكبز لـ لـ

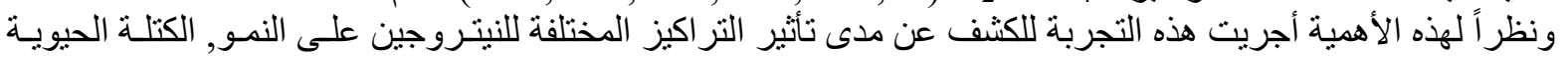

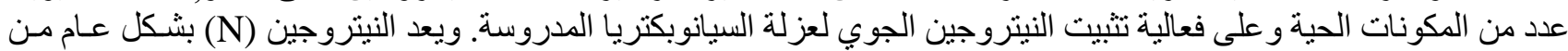

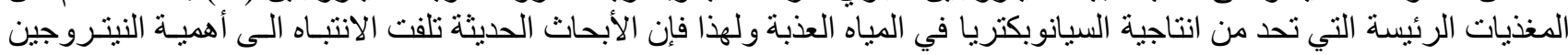
في البحيرات الصغيرة[33] وتمت اضافة

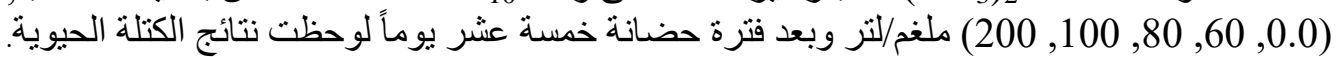

تحضير لقاح السيانوبكتريا Preparation of the Cyanobacterial inoculant

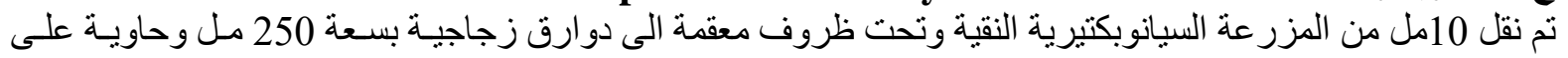

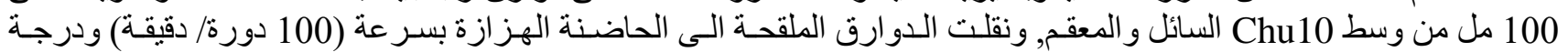

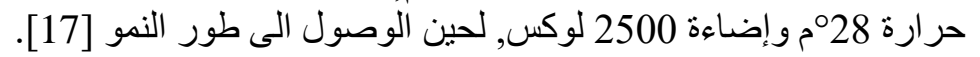

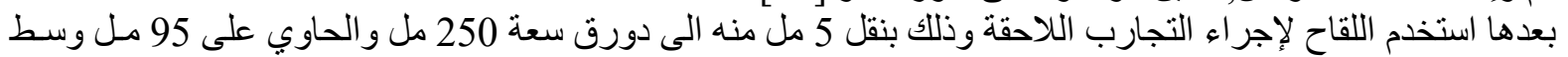

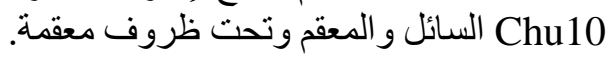
حفظ الطحلب السيانوبكتيري Cyanobacterial Isolate Save:

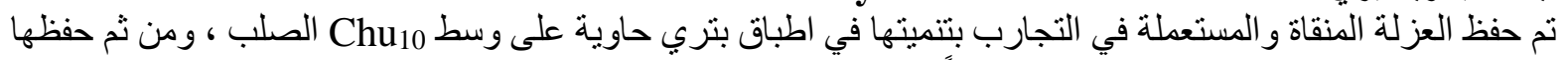

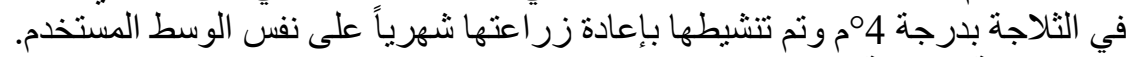
قياس الكتلة الحيوية Biomass measurement:

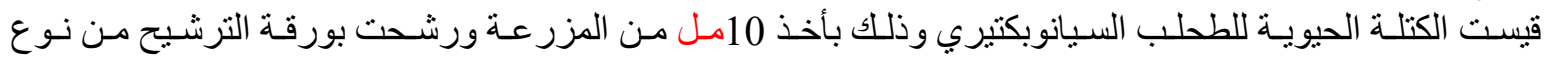
Whatman No. 1

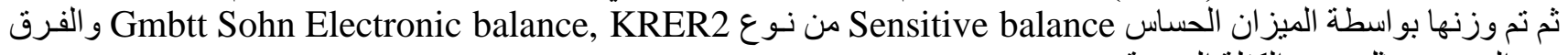

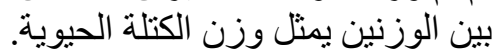

تقدير المحتوى البروتيني Determination of protein content

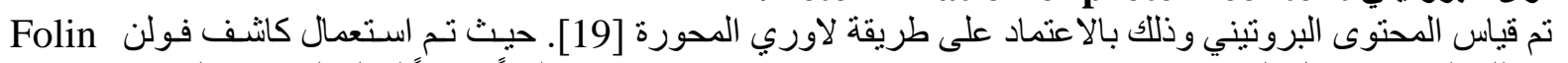

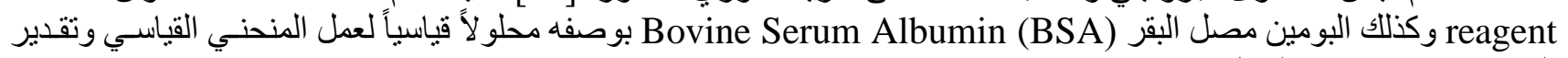
البروتين[20] كما في الثكل (1):

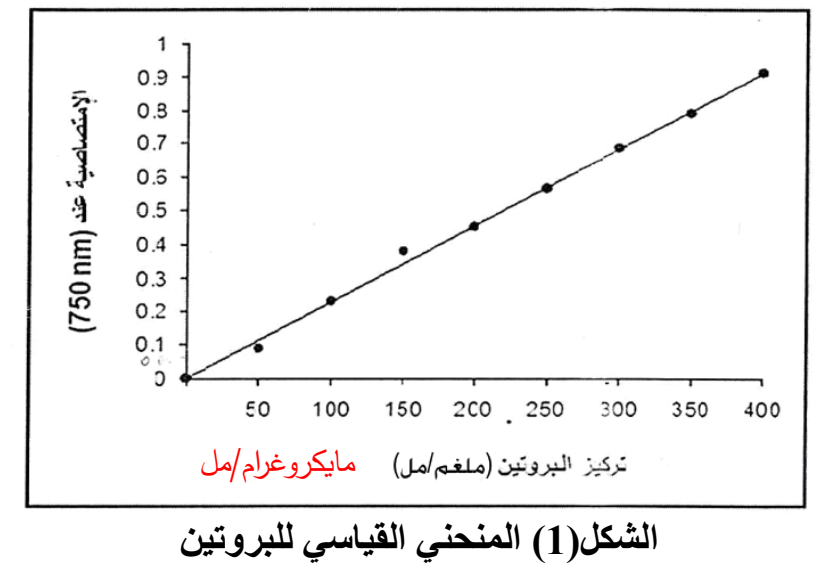

المحاليل المستخدمة لهذه التجربة موضحة في الجدول (1):

الجدول (1) المحاليل المستخدمة بطريقة فولن

\begin{tabular}{|c|c|}
\hline طريقة تحضيره & 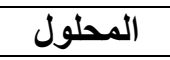 \\
\hline يخفف بنسبة 1:1 & كاثف فولن \\
\hline أذيب 0.7 غم من NaOH و 3.5 غم من Na2 $\mathrm{NaO}_{3}$ ويكمل الحجم الى 200 مل من الماء المقطر & Aحلول A \\
\hline تم اذابة 0.1 غم من ترتر ات الصوديوم- بو تاسيوم ثم اضيف لها 10 من الماء المقطر. 0.05 غم من كبريتات النحاس اللامائية CuSO في & B محلول \\
\hline يتم مزج 50 مل من محلول A مع 1 مل من محلول B & محلول C \\
\hline يحضر بنسبة 100 مايكرو غر ام/100مل من الماء المقطر & BSA \\
\hline
\end{tabular}




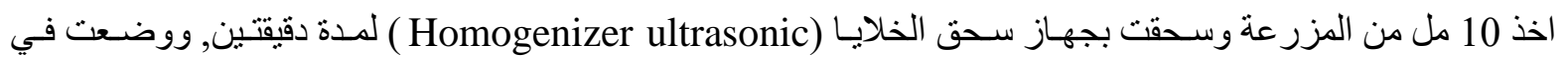

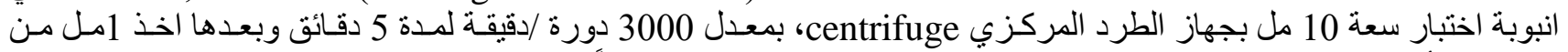

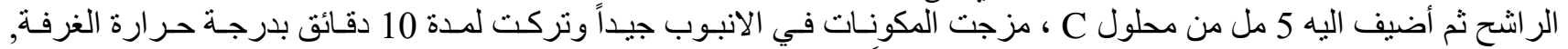

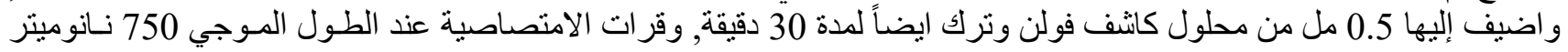

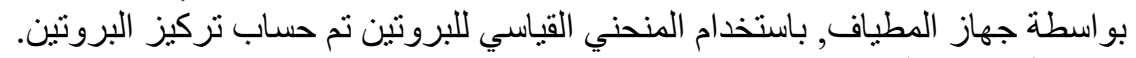
تقدير المحتوى النتروجيني Determination of nitrogen content: أجري قياس المحتوى النيتروجيني بالاعتماد على طريقة كلدهال Kjeldahal method و التي تكون على ثنلاث مر احل أساسية وهي (الهضم, التقطير, المعايرة) [21].

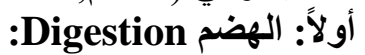

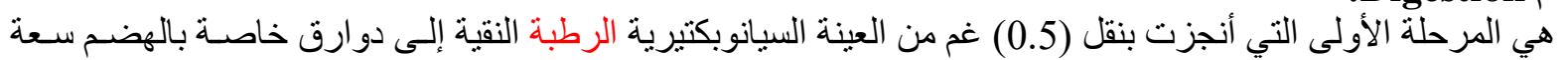

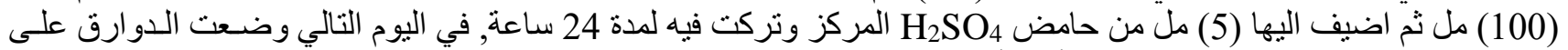

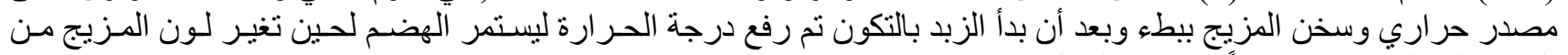
الغامق الى الفاتح (رائق جداً) كما في الثكل (2).

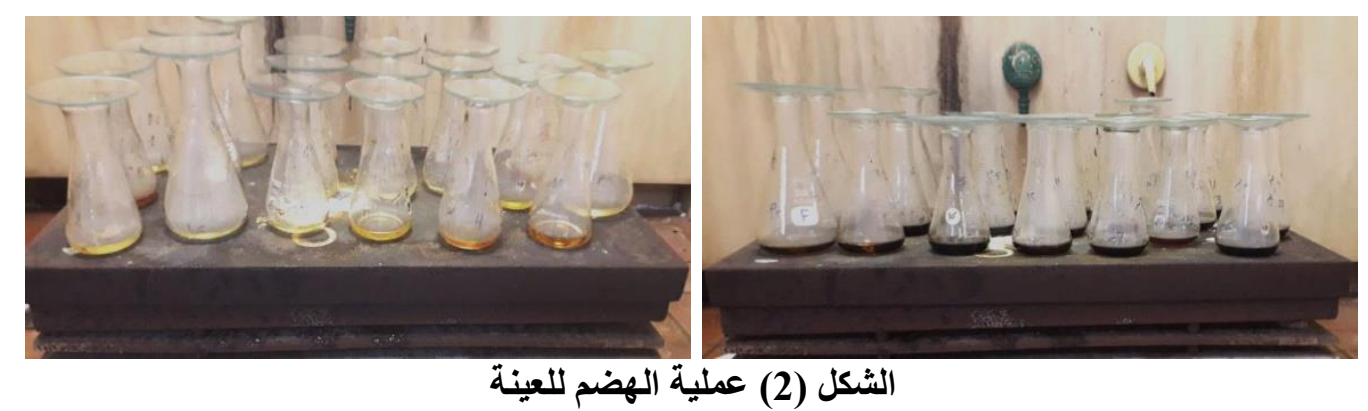

ثنانياً: التقطير Distillation:

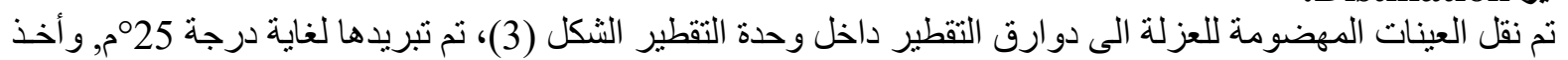

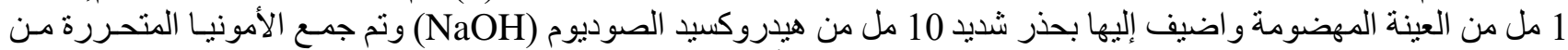

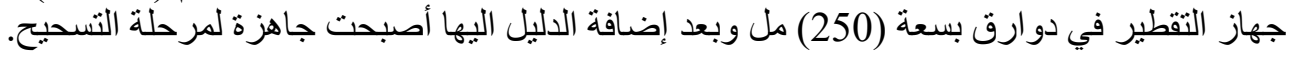

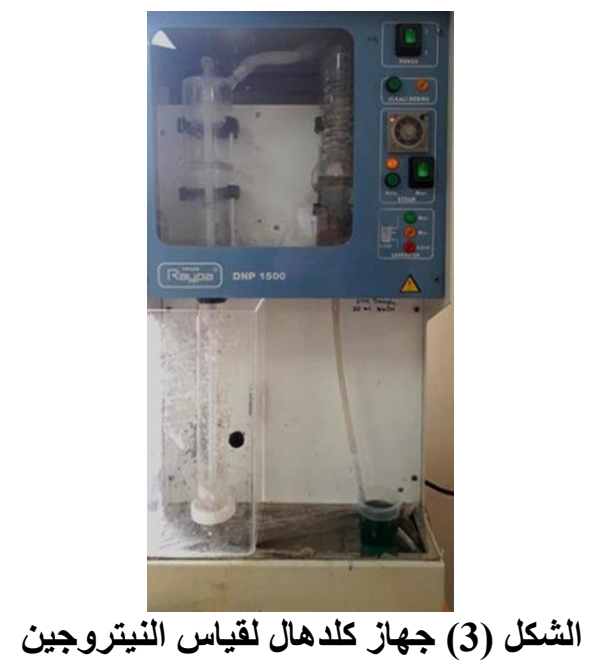

طريقة تحضير الاليل الخاص بكلدهال:

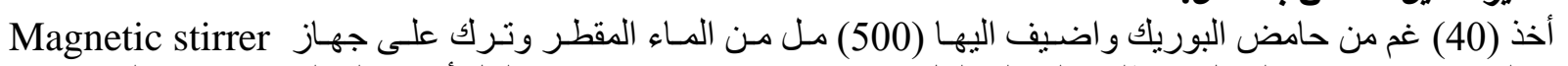

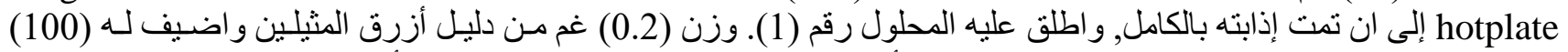

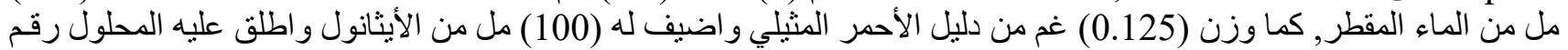

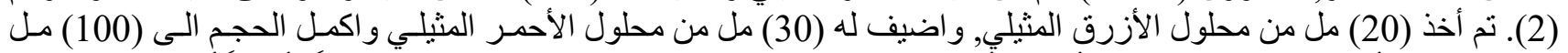

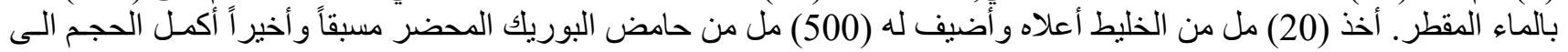


واحد لتر و الذي يكون لونه أزرق و هذا يمثل الدليل المستخدم بعملية التسحيح. خلال عملية التقطير يتغير لون الدليل مـن الأزرق الى فى

الأخضر دليل على انتهاء عملية التقطير كما هو موضح في التهر الثنل (4).

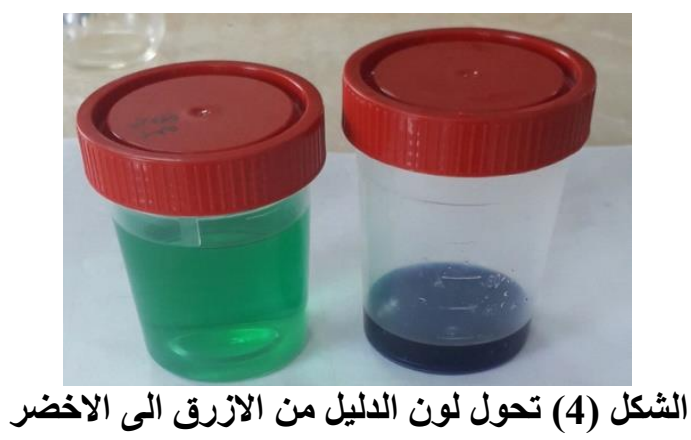

تُالثاً: المعايرة Calibration:

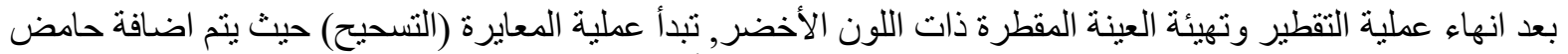
المت المستهلك لعملية التسحيح كما في النكل (5).

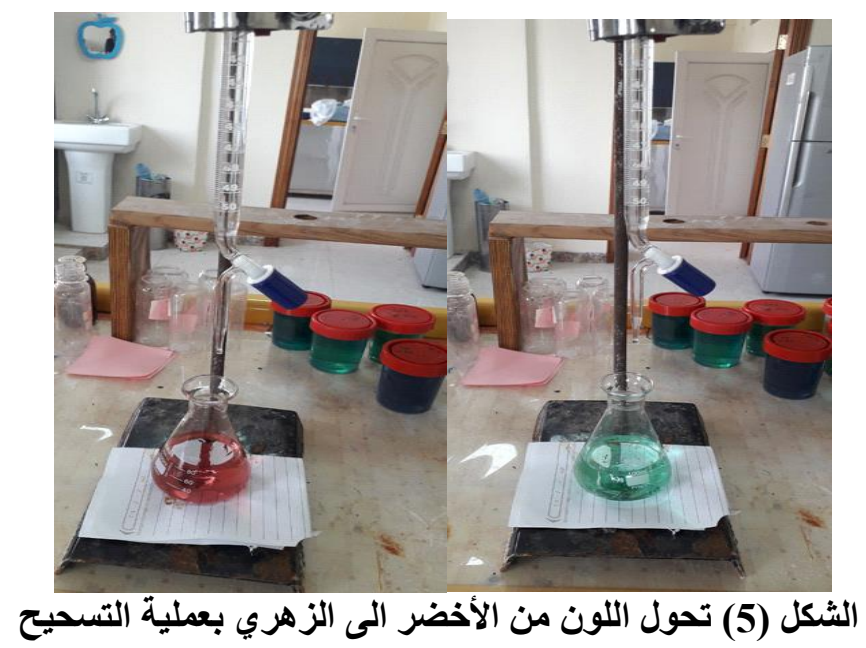

و أخير أ نم حساب النسبة المئوية لكمية النيتروجين من عزلة السيانوبكتريا المدروسة باستخدام المعادلة الآتية:

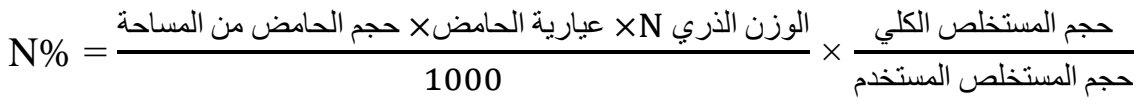

Isolation and characterization of microscopic cyanobacteria:

$$
\text { عزل وتنتوصيف والمناقشة }
$$

عزلت العينة المدروسة التي تتميز بلونهـا الأخضـر المزرق وتم فحصـها مجهريـاً بواسطة المجهر المركب وتثخيصها

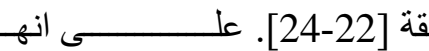
الس

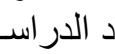

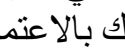

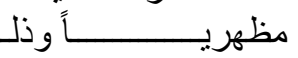
Hapalosiphon arboreus 3OW05S02

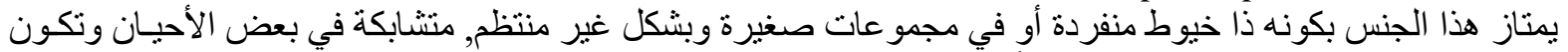

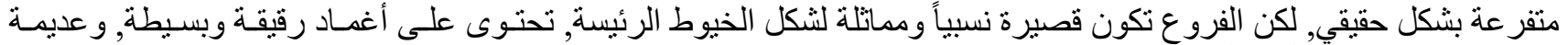

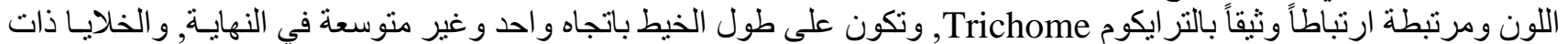

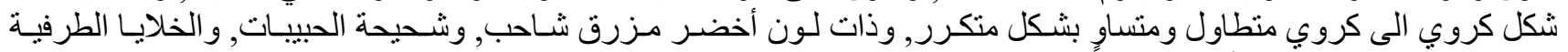

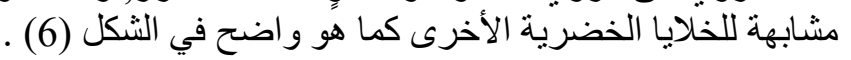




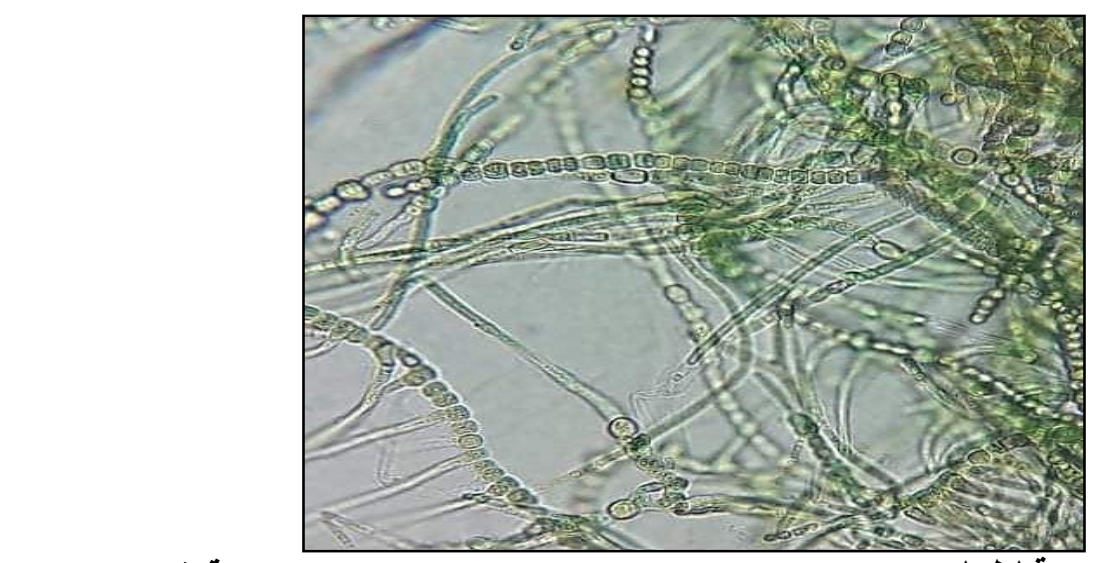

الشكل (6) صورة مجهرية لطحلب Hapalosiphon arboreus 3OW05S02 تحت قوة تكبير X40

تأثير عامل الطول الموجي للضوء على نمو الطحلب والمحتوى النتروجيني والبروتيني Effect of Light wavelength on cyanobactreium Biomass, Protein and Nitrogen content

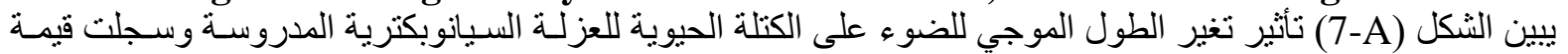

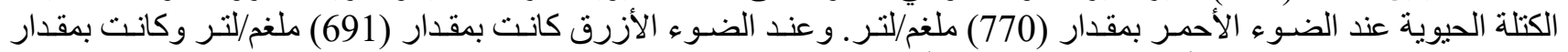

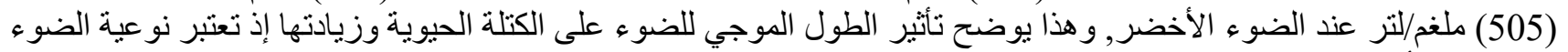
وجودته من أهم العو امل المؤثرة على الكتلة الحيوية والنمو فئلير في السيانوبكتريا و هذا ما يتطابق مع نتائج [25].

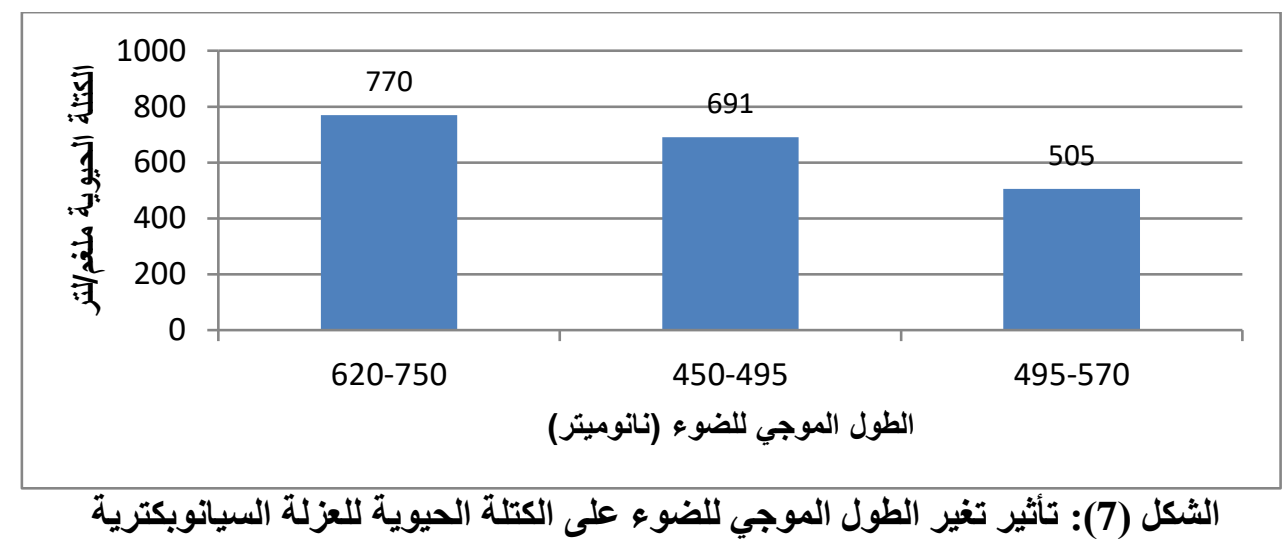

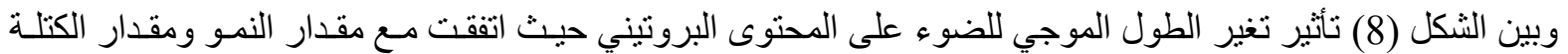

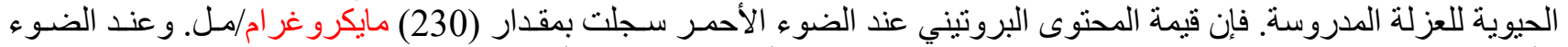

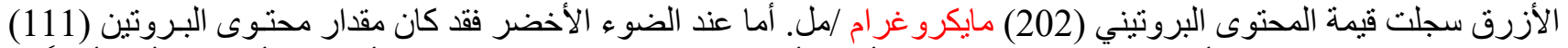

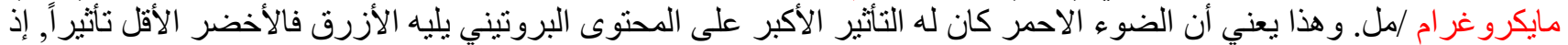

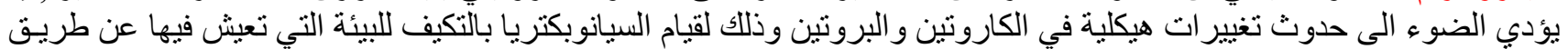

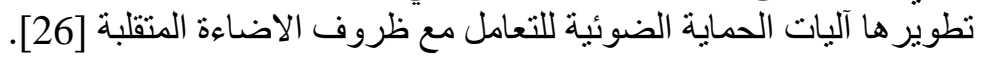

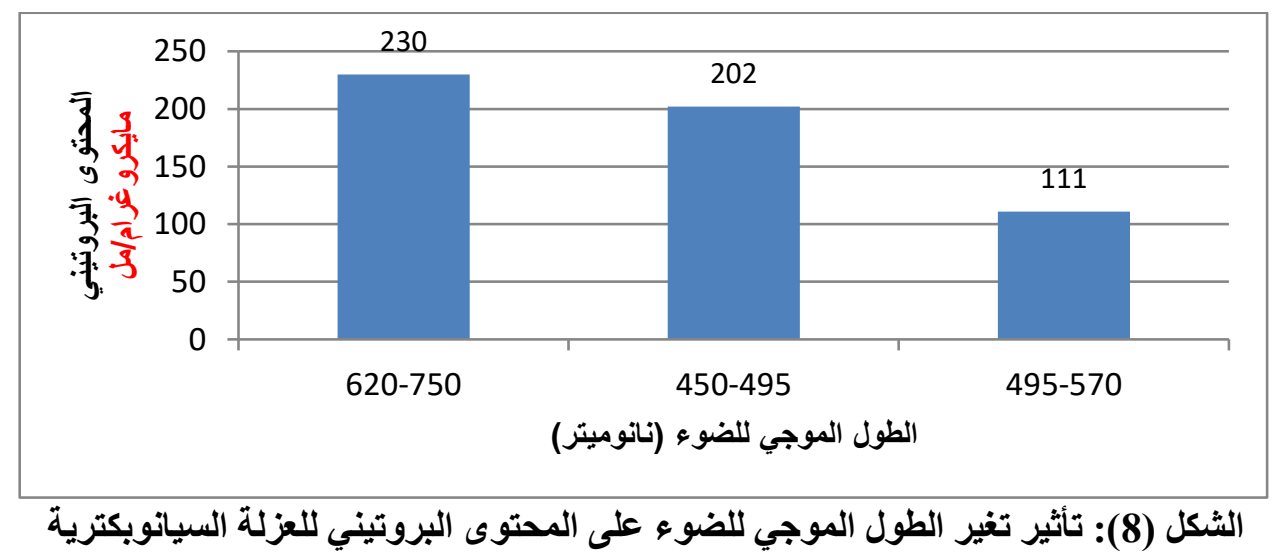




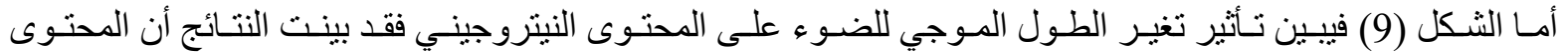

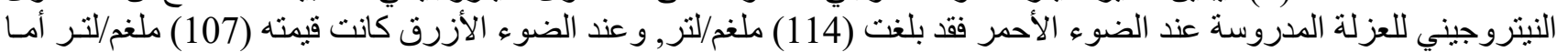

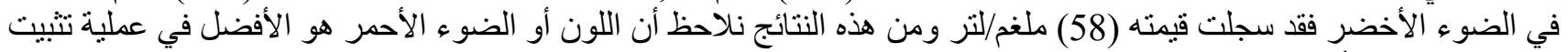

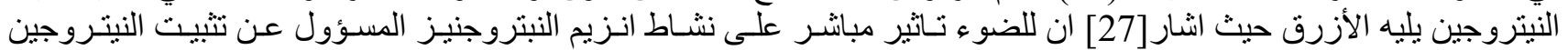
الجوي في السيانوبكتيريا.

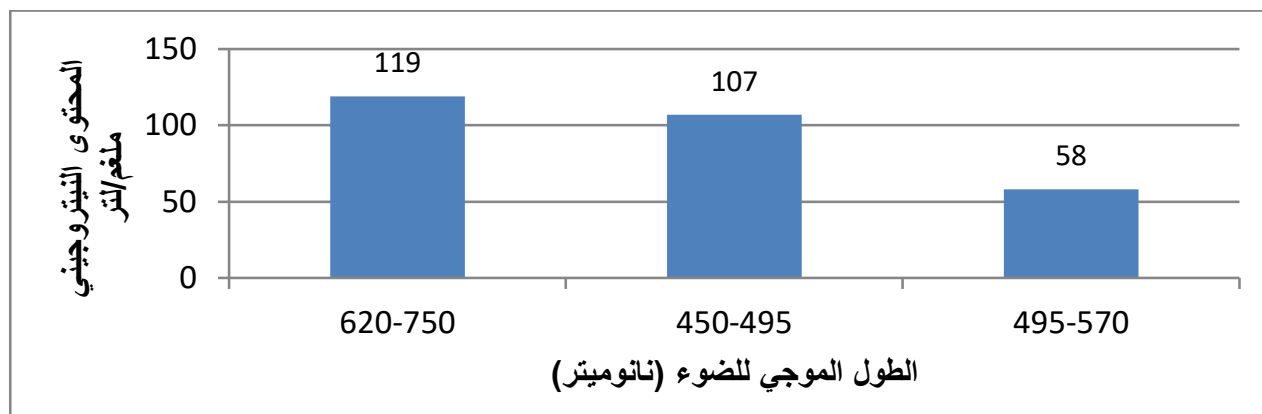

الشكل (9): تأثير تغير الطول الموجي للضوء على المحتوى النايتروجيني للعزلة السيانوبكترية

تأثير تركيز فوسفات البوتاسيوم على الكتبة الحيوية والمحتوى البروتيني والنتروجيني للطحلب

Effect of Potassium Phosphate concentration on cyanobacterium Biomass, Protein and Nitrogen content

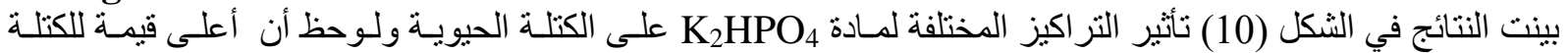

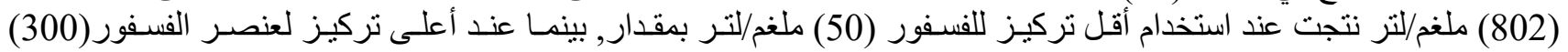

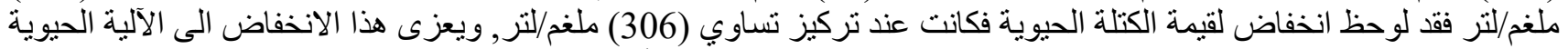

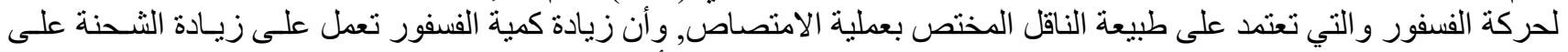

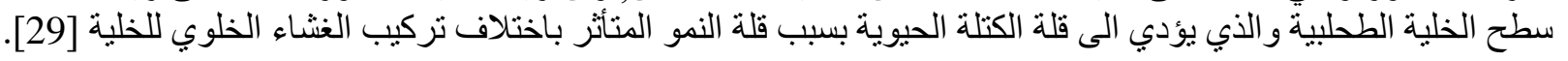

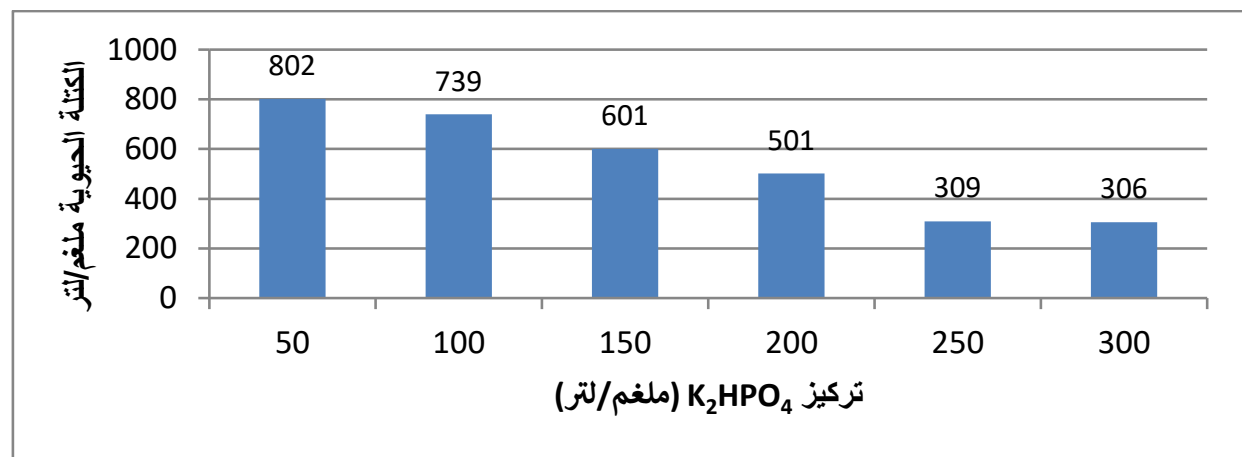

الثكل (10): تأثير التراكيز المختلفة لمادة K2HPO4 على الكتلة الحيوية

يبين الثكل (11) ناثير التركيز المختلف لمركب K2

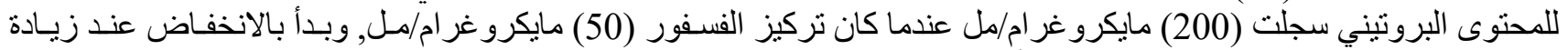

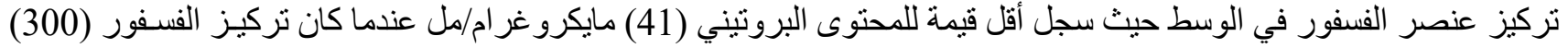

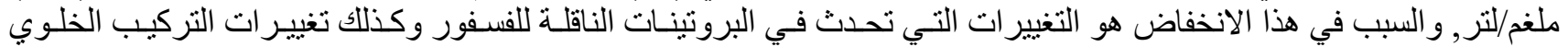

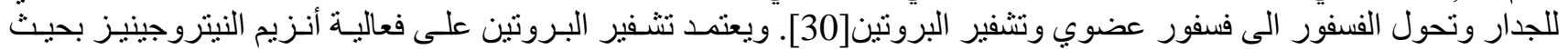

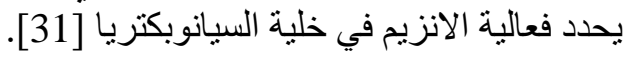




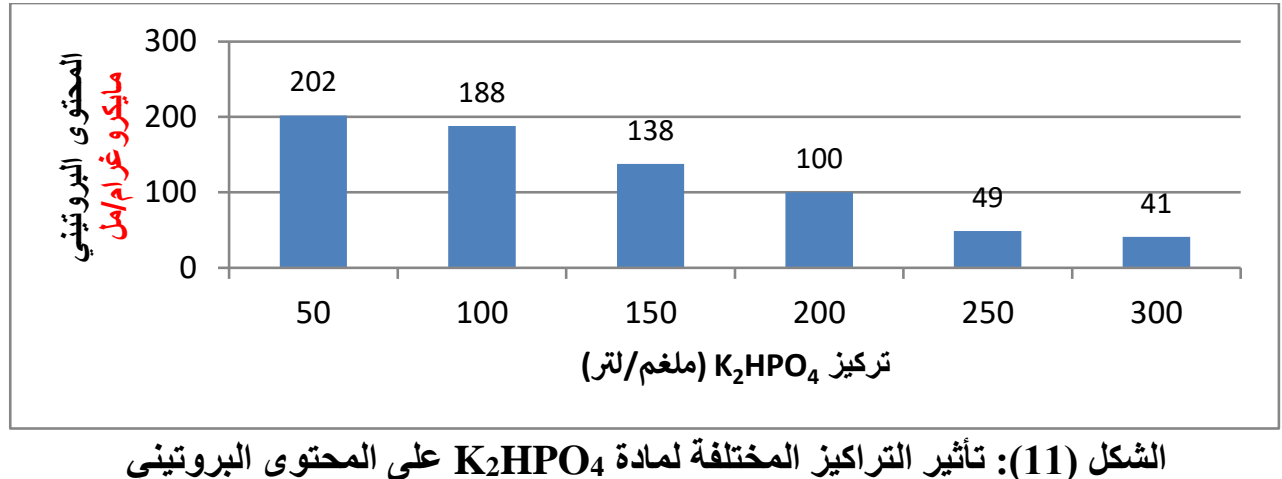

أما تأثير التر اكيز المختلفة لـ

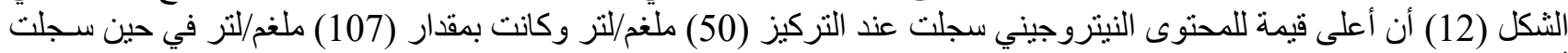

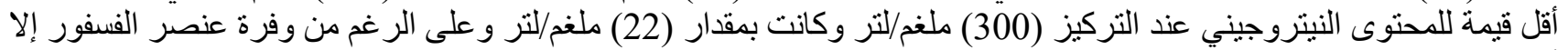

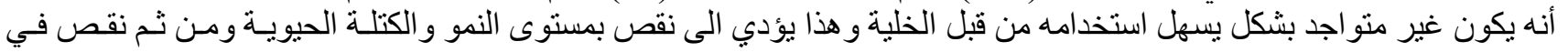

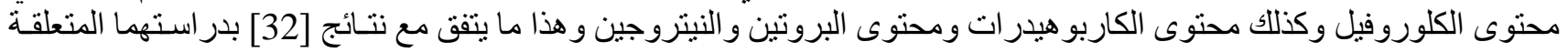

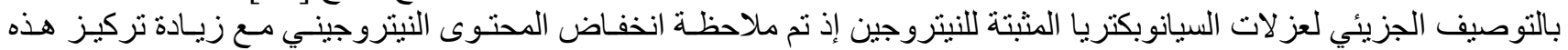

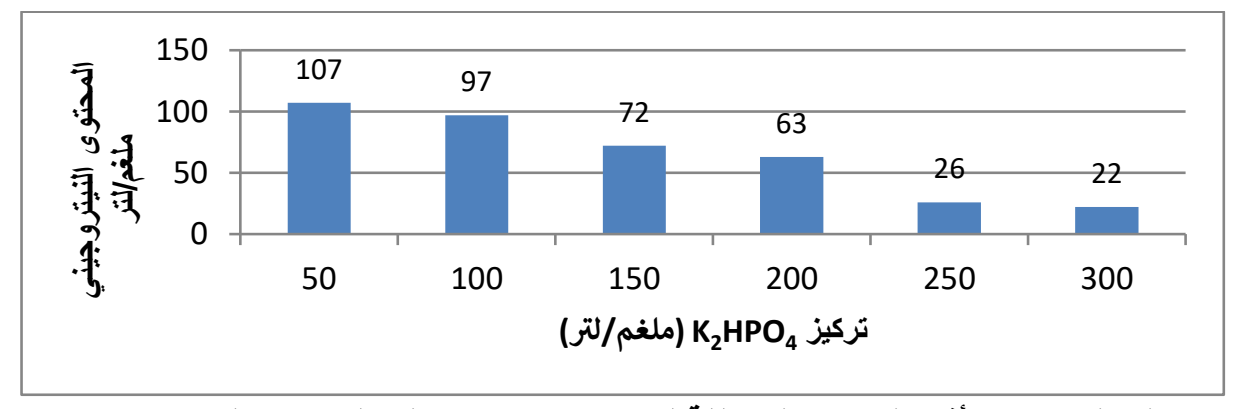

الثكل (12): تأثير التراكيز المختلفة لمادة K2HPO4 على المحتوى النيتروجيني

تأثير تركيز نترات الكالسيوم على الكتلة الحيوية والمحتوى البروتيني والنيتروجيني للطحلب السيانوبكتيري Effect of Calcium Nitrate concentrations cyanobacterium Biomass and Protein and Nitrogen content:

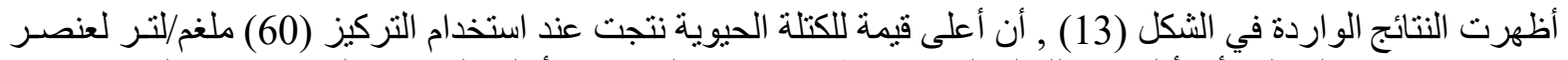

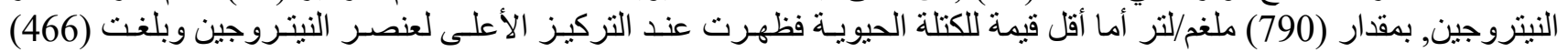
ملغم/لتر عند التركيز (200) ملغم/لتر.

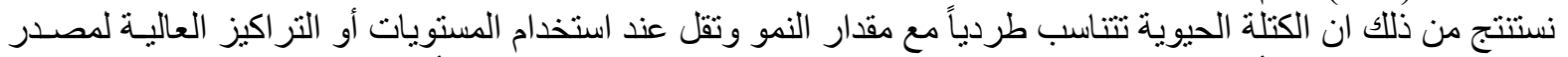

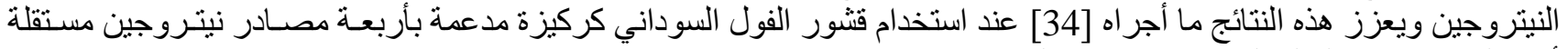
أدت الى زيادة في الكتلة الحيوية عند تنمية السيانوبكتريا.

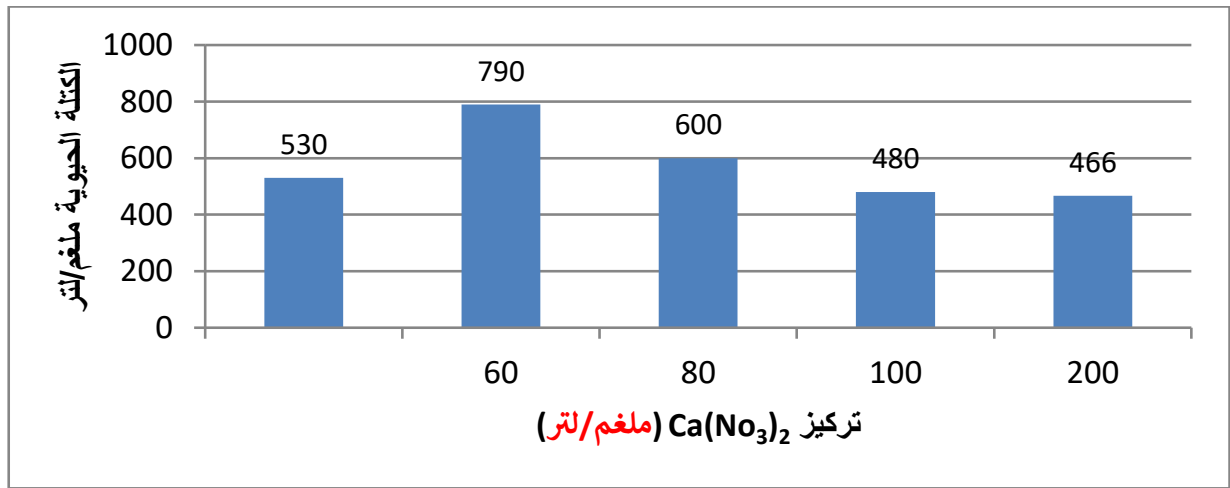

الشكل (13): تأثثر التراكيز المختلفة لمادة Ca(NO3)2 على الكتلة الحيوية 


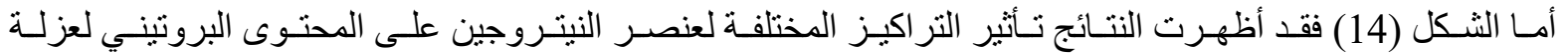

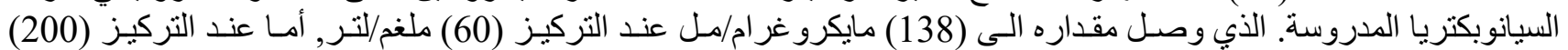

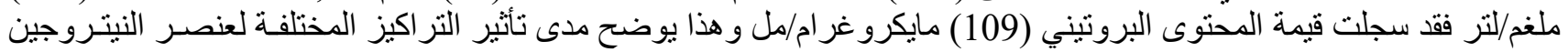

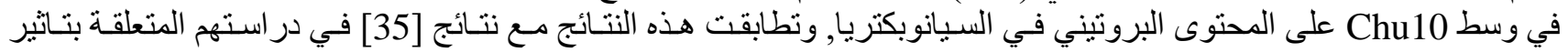

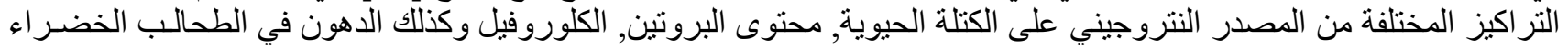
و السيانوبكتريا.

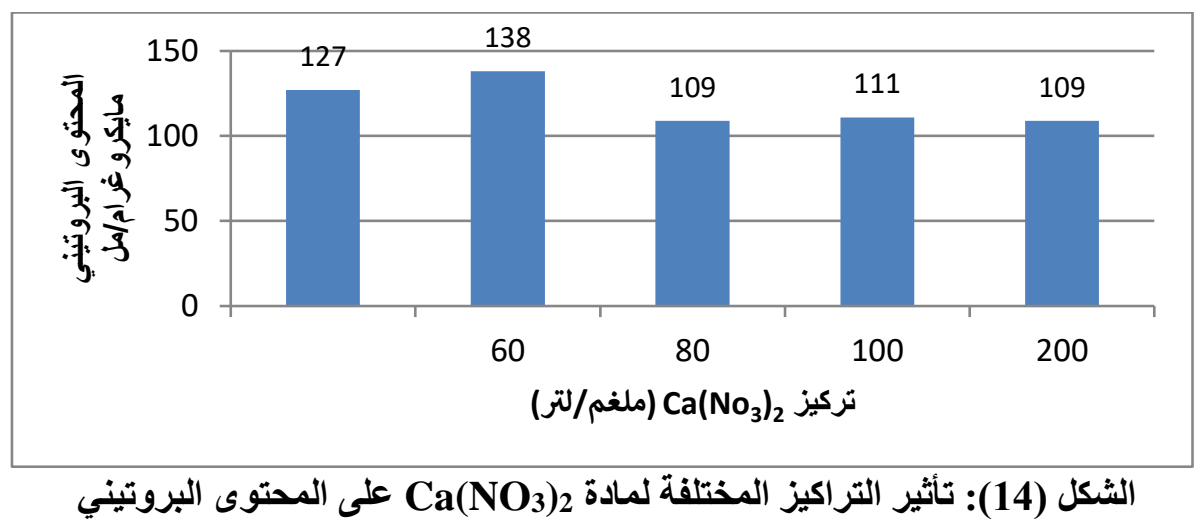

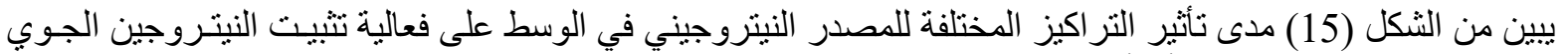

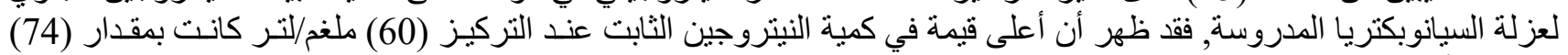

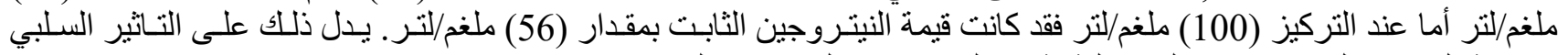

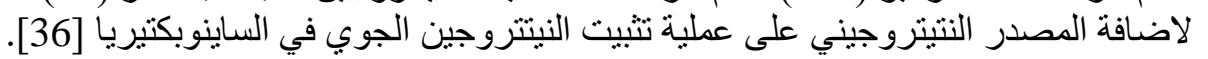

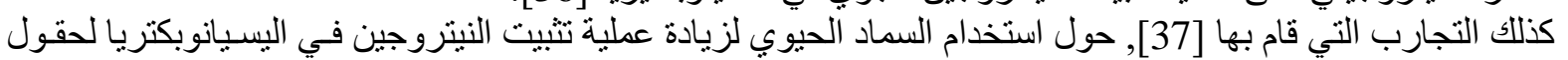

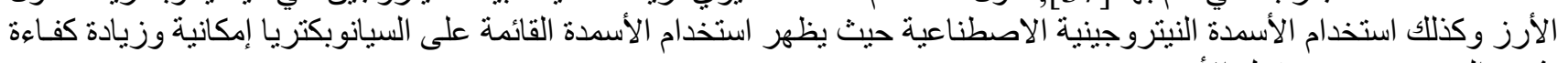
تثبيت النيتروجين في حقول الأرز.

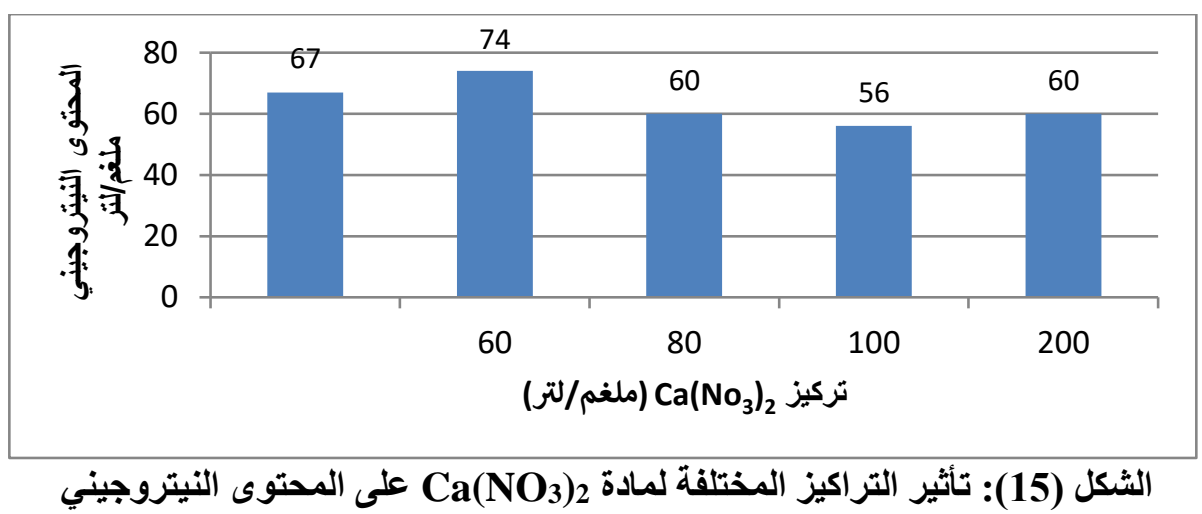

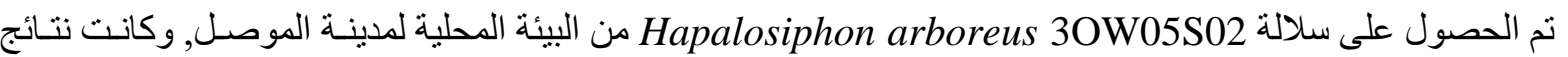

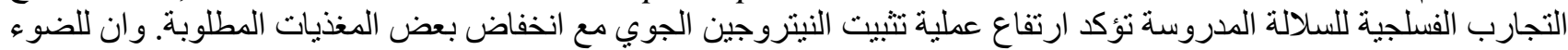

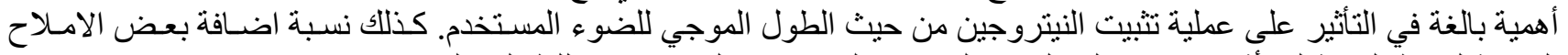

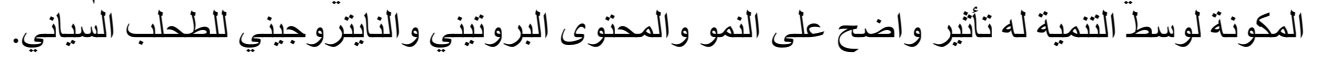

[1] ALI, G.H. "Phytoplankton (algael)". National research center, water and wast water management program, GTZ project No. 06. 3. (2008).

[2] Brouwer, P., Brautigam, A., Buijs, V.A., Tazelaar, A.O.,Van der Werf, A., Schluter, U. \& Schluepmann, H. In Plant - Science, 8, 442. (2017). 
[3] Sinha, R. International journal of Bioassays , 6, 5386-5388. 4. (2017).

[4] Snehee, S. \& Verma, M. P. The journal of plant science Research, 35 (1) 55 - 58. (2019).

[5] He , P., Cai, X., Chen, K. \& Fu, X. Annals of microbiology, 70 (1), 1-13. (2020).

[6] Miyawaki, K., Rylarkowski, P. Matsumoto Kitano, Tarkowski, P. Matsu Kato, T., Sato, S., Tarkowska, D., ... \& Kakimoto, T. National Academy of sciences 103 (44) 16598-16603. (2006).

[7] Hoffman, B.M., Lukoyanov, D., Yang, Z.Y., Dean, D.R., Seefeldt, L.C. Next Stage Chem. Rev. 114 (8): 4041-4062. (2014).

[8] Benediktsson, B., \& Bjornsson, R., Quantum Mechanics (Molecular mechanics study of Resting state Vanadium Nitrogenase : Molecular and Slectronic structure of the Iron - Vanadium Cofactor. Inorganic Chemistry. 59(16): 11514-11527. (2020)

[9] Latysheva, N., Junker, V.L., Palmer, W.J., Godd, G.A. \& Barker, D., The evolution of nitrogen fixation in Cyanobacteria. Broinformatics, 28(5): 603-606. (2012).

[10] Kulasooriya S.A. Faculty of Science, University of Peradeniya, pp. 143.(2008).

[11]Chakdar, H., \& Pabbi, S. "Cyanobacterial Phycobilins: Production, Purification, and Regulation In Frontier Discoveries and Innovations in Interdisciplinary Microbiology" (pp. 45-69). Springer New Delhi. (2016).

[12] Anderson R. A. "Algal to Culturing Techniques Amsterdam". Ed West Boothbay Harbor. (2005).

[13]Lpez, C.V.G.; Gareda, M.C.C.; Ferngdez, F.G.A.; Bustos, C.S.; Chisti, Y.; and Sevilla, J.M.F. Bio. Res. Technol., 101: 7587-7591. (2010).

[14] Hiler, A.; Plazin, J and Slyke, D.D.V., J. Biol. Chem, 176: 1401 - 1420. (1948).

[15] Al-Shahri, Y.J. Said, H.K., J Rafidain Scie., 27 (1): 95-117. (2018). (In Arabic)

[16]Rippka, R. "Isolation And Purification Of Cyanobacteria In Methods In Enzymology" (Paker, L. and Glazer, A. N. eds.), 167: 3-112. London. Academic Press. (1988).

[17] Shukrji, Hiba Khalil Saeed (2012). The impact of a number of heavy metals on some vital events of local isolates from cyanobacterium stabilizers of Oscillator, Nostoc and Anabaena, Master's thesis, Unpublished, College of Pure Sciences Education, Mosul University (In Arabic)

[18]Al-Taie, Zubaydah Mahmoud Saleh (2012). The effect of some agricultural conditions and nutrients on growth and some activities and vital components of a local isolate of Chlorella Vulgaris, Master Thesis, College of Education, University of Mosul, Iraq.(In Arabic).

[19]Lowry, O.H.; Rosebrough N. J.; Farr A.L. and Randall R. J., Biol. Chem., 193: 265 275. (1951).

[20] Sadasivam, S. \& Manickam, A. "Biochemical method" $3^{\text {ed }}$, New Age, International (P) Ltd. Publisher app. 52. (2008).

[21] Silva , T.E. d.; Detmann, E; Franco, M. and Rocha, G. C. Acta Scientiarum Ani. Sci. 38 (1): 45 51. (2016).

[22]Bold, H. C. \& Wynne, M. J. "Introduction to the algal structure and reproduction". $2^{\text {nd }}$ prenticeHall. In C. Englewood Cliffs. New Jersey, U.S.A. (1985).

[23] Prescott G. W., The algal : A Review Teds W. E street and H. B. Glass Houghton Mifflin Co. Boton. (No.04; QK566, p7). (1968),

[24]Desikachary, TV. "Cyanophyta ICAR Monographs" on algae Indian Council of Agricultural research, New Delhi, p 686. (1959).

[25]Barnett, J.Z. Effects of Light Quality and light Quantity on the Kinetics of a Louisiana Native microalgat Cyanobacterial Co-Culture. (2015).

[26] Kirilovsky, D., \& Kerfeld, C.A. (BBA)- Bioenergetics, 1817 (1) 158-166. (2012).

[27] Weare, N.M., Benemann, J.R. Archive for Mikrobiol. 93(2), 112-118. (1973).

[28]Hoffman, P. F. Geobiology 14 (6): 531-542., (2016).

[29]Dittrich, M and Li, J., Enu. Micr. 21 (2): 572-583. (2019).

[30]Raven, J., Plant Rev 48: 67-79. (2018).

[31] Stanton, D.E.; Batterman, S.; Fisher, J.C.V. and Hedin, L.S., Ecology 100 (9): 279-291. (2019). 
[32] Al-Qassimi, A.H.; Abdul-Razzaq S.. Molecular characterization of intra-diameter isolates of bio-nitrogency and the study of a number of psychochemical variants affecting them, an unpublished Doctoral thesis, College of Education of Pure Sciences, University of Mosul, (2020). (In Arabic)

[33]Hu, T. L., \& Wu, S. C. Bioresource technology, 77 (1), 93-95. (2001).

[34] Mishar, A., \& Kumar, S. Biochemistry, 42 (4), 681-685. (2007).

[35]Piorreck, M., Baasch, K.H., \& Pohl, P. Phytochemistry, 23 (2), 207-216. (1984).

[36]Berg, A., Danielsson, A., \& Svensson, B.H. Plant and Soil, 362 (1-2), 271-278. (2013).

[37]Pereira, S., Zille, A., Micheletti, E., MoradasFerreira, P., De philipis, R. \& Tamagnini, p. FEMS microbiology reviews, 33(5):917-941. (2009). 